\title{
Analysis of incidents notified in a general hospital
}

\author{
Análise da ocorrência de incidentes notificados em hospital-geral \\ Análisis de la ocurrencia de incidentes notificados en hospital-general
} \begin{abstract}
Mirela Lopes de Figueiredo ${ }^{1, \text {,I }}$, Carla Silvana de Oliveira e Silva ${ }^{1, \text {,II, }}$
Maria Fernanda Santos Figueiredo Brito", Maria D'Innocenzo'
' Universidade Federal de São Paulo, Paulista Nursing School, Postgraduate Program in Health Sciences. São Paulo, Brazil.

"Universidade Estadual de Montes Claros, Center for Biological and Health Sciences, Department of Nursing. Montes Claros, Minas Gerais, Brazil.
\end{abstract}

\begin{abstract}
How to cite this article:
Figueiredo ML, Oliveira e Silva CS, Brito MFSF, D'Innocenzo M. Analysis of incidents notified in a general hospital. Rev Bras Enferm [Internet]. 2018;71(1):111-9. DOI: http://dx.doi.org/10.1590/0034-7167-2016-0574
\end{abstract}

Submission: 11-23-2016

Approval: 04-05-2017

\begin{abstract}
Objective: To evaluate the incidents spontaneously notified in a general hospital in Minas Gerais. Method: Retrospective, descriptive, quantitative study performed at a general hospital in Montes Claros - Minas Gerais State. The sample comprised 1,316 incidents reported from 2011 to 2014 . The data were submitted to descriptive statistical analysis using Statistical Package for the Social Sciences version 18.0. Results: The prevalence of incidents was 33.8 per 1,000 hospitalizations, with an increase during the investigation period and higher frequency in hospitalization units, emergency room and surgical center. These occurred mostly with adult clients and relative to the medication supply chain. The main causes were noncompliance with routines/protocols, necessitating changes in routines and training. Conclusion: There was a considerable prevalence of incidents and increase in notifications during the period investigated, which requires the attention of managers and hospital staff. Nevertheless, we observed development of the patient safety culture.
\end{abstract}

Descriptors: Patient Safety; Safety Management; Quality of Health Care; Quality Assurance in Health Care; Nursing.

\section{RESUMO}

Objetivo: avaliar os incidentes notificados espontaneamente em um hospital-geral de Minas Gerais. Método: estudo retrospectivo, descritivo, quantitativo, realizado em hospital-geral de Montes Claros - MG. A amostra foi composta de 1316 incidentes notificados entre 2011 a 2014. Os dados foram submetidos à estatística descritiva no software Statistical Package for the Social Sciences versão 18.0. Resultados: A prevalência de incidentes foi de 33,8 por 1.000 internações, tendo sido evidenciados aumento ao longo do período investigado e maior frequência nas unidades de internação, no setor de emergência e centro cirúrgico. Houve maior ocorrência em clientes adultos e relativos à cadeia medicamentosa. As principais causas foram o descumprimento da rotina/protocolo, sendo necessárias mudanças na rotina e no treinamento. Conclusão: Houve considerável prevalência de incidentes e aumento de notificações no período investigado, o que requer atenção dos gestores e colaboradores, apesar de observado o desenvolvimento da cultura de segurança do paciente.

Descritores: Segurança do Paciente; Gestão da Segurança; Qualidade da Assistência à Saúde; Garantia da Qualidade dos Cuidados de Saúde; Enfermagem.

\section{RESUMEN}

Objetivo: evaluar los incidentes notificados espontáneamente en un hospital general de Minas Gerais. Método: estudio retrospectivo, descriptivo, cuantitativo, realizado en hospital general de Montes Claros - MG. La amuestra fue compuesta de 1316 incidentes notificados entre 2011 y 2014. Los datos fueron sometidos a la estadística descriptiva en softwareStatisticalPackage for the Social Sciences versión 18.0. Resultados: La prevalencia de incidentes fue de 33,8 por 1.000 internaciones, habiendo sido evidenciados aumento a lo largo del período investigado y mayor frecuencia en las unidades de internación, en el sector de urgencia y centro quirúrgico. Hubo mayor ocurrencia en clientes adultos y relativos a la cadena medicamentosa. Las principales causas fueron el incumplimiento de la rutina/protocolo, siendo necesarios cambios en la rutina y en el entrenamiento. Conclusión: 
Hubo considerable prevalencia de incidentes y aumento de notificaciones en el período investigado, lo que requiere atención de los gestores y colaboradores, a pesar de observado el desarrollo de la cultura de seguridad del paciente.

Descriptores: Seguridad del Paciente; Gestión de la Seguridad; Cualidad de la Asistencia a la Salud; Garantía de la Cualidad de los Cuidados de Salud; Enfermería.

\section{INTRODUCTION}

Safety has a particular relevance in health care and, in this sense, the patient safety culture in an institution has a great impact on the quality of care ${ }^{(1)}$. Hospital institutions are increasingly concerned about ensuring quality care for their clients. In this context, patient safety has been highlighted with the implementation of measures to prevent exposure to risks, as well as harm resulting from health care. The hospital space presents numerous health risks to patients, which can aggravate their health status. It is the responsibility of professionals to identify risks in each unit, to guarantee the clients' safety and restoration of their health, besides avoiding or minimizing possible intercurrences during their stay in the institution ${ }^{(2-3)}$.

In October 2004, the World Health Organization (WHO) established the "Global Patient Safety Alliance", which aims to raise awareness for improved safety in care, as well as the development of health care policies and strategies ${ }^{(4)}$. The development of a safety culture, the practice of record taking, discussion of the circumstances in which incidents occur, as well as the professional and organizational conduct in these cases, are a path to be followed for the transformation of reality in health institutions. The occurrence of incidents can be minimized through changes in managerial and professional attitudes, strengthening of leadership and knowledge, improved accessibility, quality and use of medical and hospital material, and competent and productive maintenance of professionals $\mathrm{s}^{(5)}$.

The WHO emphasizes that adverse events should be widely researched, encompassing: from the factors that contribute to their occurrence, characteristics of the patients, type of incident observed, detection mechanisms, factors that can mitigate events, evolution of the patients, organizational followup; to improvement actions, their implementation and results from these actions ${ }^{(6)}$. In addition, there is a greater awareness at the national level that professionals need to be trained regarding the measures to be taken in the face of failures, as well as being encouraged to take an honest attitude towards error, without fear of punishment and to be effectively involved in patient care $\mathrm{c}^{(\mathrm{)})}$.

Another important factor is the need to implement a notification culture in the institutions so that information on failures or incidents and adverse events are clear and complete, allowing a better analysis of their causes ${ }^{(8)}$. However, a punitive culture still prevails in situations that culminate in errors or adverse events. In this context, communication barriers imply greater adverse occurrences, since feedback of information on the consequences of adverse events and the proposal of more effective alternatives for their management does not occur, which in turn prevents a satisfactory resolution ${ }^{(3,7)}$.
Thus, it is fundamental to incorporate the issue of patient quality care and safety into the governmental and academic agenda, as well as the training and updating of professionals regarding the importance of reliable and complete registration in health information systems. Periodic re-evaluations of information systems are also necessary in order to be effective mechanisms for measuring the performance and quality of the services offered. Such measures impact the restructuring of health services, with a particular focus on the quality of care, and not only on reimbursement for services rendered ${ }^{(9)}$. Tracking incident-related factors is difficult, as recent studies point to flaws in record keeping, making it impossible to investigate further into causes and consequences. However, the simple act of recording shows that health professionals recognize and identify the incident, in order to adopt preventive measures for possible corrections, reduction and/or elimination, and also to follow the development of actions to improve health practice ${ }^{(10)}$.

The present study aimed to evaluate the spontaneously reported incidents in a general hospital in Minas Gerais.

\section{METHOD}

\section{Ethical aspects}

The ethical procedures were followed, according to Resolution $n^{\circ} 466$, of December 12, 2012. The research project was approved by the Research Ethics Committee of the Federal University of São Paulo (UNIFESP), on October 10, 2013. Formal authorization to carry out the study was obtained from the hospital.

\section{Design, place of study and period}

This is a retrospective and descriptive study, with a quantitative approach, performed in a philanthropic, tertiary level, general-hospital, located in the city of Montes Claros, Minas Gerais State, with a capacity of 360 beds and an average of 10,245 patient days per month. It has certifications as a teaching hospital and is Accredited with Excellence by the Organização Nacional de Acreditação (ONA) [National Accreditation Organization], besides being part of the Rede Sentinela [Sentinel Network]. The institution is a reference throughout the region of Northern Minas Gerais and South of Bahia State. It attends a population that surpasses 1.5 million inhabitants for medium and high complexity attendance in various specialisms, namely: neurology, cardiology, gynecology, obstetrics, oncology, orthopedics, general practice, pediatrics, burn treatment, hemodynamics, chemotherapy, radiotherapy, renal replacement therapy/hemodialysis.

In 2005, the hospital senior management, decided to seek ONA certifications, with a focus on improving the quality of care provided to patients. From then on, the Quality Office (QO) was created, with responsibility for the hospital's quality 
and risk management guidelines. The QO consists of a quality manager, a nurse, three administrative staff and two nursing students. It is subordinated, hierarchically to a Quality Board.

Notification of incidents is carried out spontaneously and anonymously by completing a computerized file, denominated the Notification Form, available on the SAS Interact system. This software is used for strategy management, operational performance management, quality management, skills and risks. They can be performed on any computer of the institution. After receiving the Notification Cards online, the QO classifies the type of incident, once the register is accepted by the system it assigns a person responsible for follow-up, sets the date for analysis and manages the deadlines. Usually, the person in charge is the supervisor or manager of the sector where the incident occurred. After analysis, the incidents are presented to the Risk Committee, composed of the manager and nurse of the QO, by professionals representing various areas, such as the ombudsman, nursing coordination, clinical and care director, and representatives of the sector in which the incident occurred. This commission then validates or not the analysis performed.

The data were collected by the researcher and a properly trained auxiliary, from March to December 2015.

\section{Sample, inclusion and exclusion criteria}

This study analyzed a total of 1,340 spontaneous reports of incidents recorded from 2011 to 2014. Probabilistic type sampling was used with the stratified random sampling method and proportional sharing. In this sense, each year constituted a population stratum and their respective numbers of incidents corresponded to the sample units, which were drawn according to the listing in the hospital database. The confidence level was set at $95 \%$ with margin of error of plus or minus 2 percentage points. It was necessary to exclude 24 notifications due to insufficient details, incomplete entries or because they were discarded by the QO as "rants" (according to the description in the notification). Thus, the final sample amounted to 1,316 spontaneous reports.

\section{Study protocol}

For a better understanding of the study, some information to define the variables is needed:

- Age group: Newborns (NB) - 0 to 28 days; Child - 29 days to 12 years, 11 months and 29 days; Adolescent - 13 to 18 years, 11 months and 29 days; Adult - from 19 to 64 years, 11 months and 29 days; Elderly - over 65 years old.

- Notified Sector: Emergency, Neonatal and Pediatric Intensive Care Center (ICU), Coronary ICU, General ICU, Semi-Intensive Care Unit, Hospitalization Units, Pediatrics, Nursery, Maternity, Obstetric Center (OC), Surgical Center (CC), Transfusion Agency, Nephrology, Oncology, Clinical Directorate, Nutritional Therapy, Clinical Engineering, Hospitality, Ambulatory and other Diagnostic Services (endoscopy, graphic methods).

- Shift: Morning - from 07:00 to 12:59; Afternoon - from 13:00 to 18:59 minutes; Night - from 19:00 to 06:59.

- Days of the week: Sunday, Monday, Tuesday, Wednesday, Thursday, Friday and Saturday.
- Type of harm: Degree I: catastrophic, involves the occurrence of death associated with the event; Degree II: permanent harm; Degree III: temporary harm. It is necessary to be clear, to generate new care behavior, to cause injury, to increase the days of hospital stay, to cause serious psychological harm; and Grade IV: does not affect the client (near miss).

- Types of incidents: Drug supply chain (steps - prescription, dispensing, preparation, administration, checking and dispensing); Fall (bed, chair, own height, bathroom); Pressure ulcer (PU) (PU, Braden - low risk, moderate risk, high risk); Other skin lesions; Surgical procedure (relation with laterality); Transfusion process; Unplanned withdrawal of catheter, drain, tube or catheter; Identification of patient; Loss of sample; Bruise; Extravasation; Delay in exam/procedure completion; Prolonged fasting; Failure to release the technical report; Evasion; Technical or equipment/material handling failure; Failure to identify material/instruments; Related to childbirth; Nutritional therapy; Healthcare related infection; Failure during technique, procedure or transportation; Death and Others.

- Causes: Six types of causal factors - Task or Technology Factors (absence of routine/protocol, inadequate functioning of materials/equipment) - were considered based on QO guidelines; Workplace factors (overloading, inadequate staffing, inadequate physical environment); Individual Factors (employee/team insufficient training, omission, noncompliance with routine/ protocol); Time Factors (communication failure); Organizational and Management Factors (absence of equipment/materials); Patient Factors (inherent patient risk).

- Actions: Perform training or guidance, follow the existing routine/protocol, modify routine/protocol, create and deploy form/check list, perform process interaction, acquire/requisition material/equipment and/or staff, clinical director intervention, perform preventive/corrective maintenance of equipment/materials.

Since it was a free text for the presentation of the event, written by the notifying professionals, the classification of types and causes was carried out by the first researcher, using the definitions in Resolution RDC No. 36, dated July 25, 2013 ${ }^{(11)}$, in addition to those defined in the literature, in addition to the researcher's personal experience for comprehending the reported situations.

In this research, concepts were adopted according to the international taxonomy of patient safety, published by the World Health Organization $(\mathrm{WHO})^{(11)}$ : Patient safety - minimizing the risk of unnecessary harm associated with health care; Risk - understood as the probability of an incident occurring; Incident - an event or circumstance that may have resulted or resulted in unnecessary harm to the patient, which may be a reported circumstance; A near miss, an incident that reached a patient but without harm to the patient, or when there is harm to the patient known as an adverse event; Adverse event (AD): an incident that results in harm to the patient; Near miss: incident that did not reach the patient; No harm event: the incident reached the patient but did not cause discernible harm; Notifiable circumstance (reportable 
incident): circumstance in which there was significant potential for harm, but the incident did not occur; Adverse reaction: unexpected harm resulting from a justified action, in which the correct process was followed for the context in which the event occurred; Error: defined as a failure to execute a plan of action as intended or an incorrect plan; Harm - impairment of the structure or function of the body and/or any effect thereof, including illness, injury, suffering, death, disability or dysfunction, and may be physical, social or psychological.

The data collection was done by reading the information sheets and recording the information in an Excell ${ }^{\circledR}$ spreadsheet prepared for the study.

\section{Analysis of results and statistics}

After data collection, the data were organized into a database in the Excell ${ }^{\circledR}$ program and later exported to the Statistical Package for the Social Sciences (SPSS) software version 18.0, in which the analyzes were performed using descriptive statistics.

\section{RESULTS}

The sample analyzed in this study was composed of 1316 incidents reported spontaneously in the period from 2011 to 2014 in the general hospital. The prevalence reached 33.8 occurrences per 1,000 admissions. It was observed that the number of notifications increased over the years: $20.4 \%$; $18.5 \% ; 44.8 \%$; and $48.2 \%$ in 2011, 2012, 2013 and 2014, respectively. The most frequently reported types of incidents were those related to the medication supply chain (18.9\%), followed by pressure ulcers (13.4\%) and failures during technique/procedure/transportation (11.7\%), as presented in Table 1.

In relation to the sectors involved for the analysis of occurrences, the highest number of reports were presented by the hospitalization units $(21.1 \%)$, followed by emergency $(10.6 \%)$ and surgical centers (8.6\%). Regarding the shift, $36.8 \%$ of the incidents occurred at night, $32.7 \%$ in the morning shift and $30.5 \%$ in the afternoon, but only $77.4 \%$ of the reports analyzed contained this information. Regarding incidents according to age group, the most affected were adults (36.7\%), followed by newborns (30.3\%) and elderly (19.5\%); however, only $35.9 \%$ of the notifications contained such information. There was a significant reduction in the recording of this data over the years, due to a change in the electronic form in 2012, when the specific field ceased to exist. When analyzed the type of harm caused, the incidents generated mainly temporary harm $(79.6 \%)$, followed by Near misses or no harm incidents $(17.9 \%)$. These results are presented in Table 2 .

Incidents involving the medication supply chain were the most frequent and these were classified mainly as Grade III, $82.2 \%$ (Table 3 ).

Table 1 - Types of incident according to year of occurrence, Montes Claros, Minas Gerais, Brazil, 2015

\begin{tabular}{|c|c|c|c|c|c|}
\hline \multirow[b]{2}{*}{ Type of event } & \multicolumn{4}{|c|}{ Year of occurrence } & \multirow{2}{*}{$\begin{array}{l}\text { Total } \\
\text { n (\%) }\end{array}$} \\
\hline & $\begin{array}{l}2011 \\
\text { n (\%) }\end{array}$ & $\begin{array}{l}2012 \\
\text { n (\%) }\end{array}$ & $\begin{array}{l}2013 \\
\text { n (\%) }\end{array}$ & $\begin{array}{l}2014 \\
\text { n (\%) }\end{array}$ & \\
\hline Medication supply chain & $46(18.5)$ & $27(10.8)$ & $70(28.1)$ & $106(42.6)$ & $249(100.0)$ \\
\hline Falls & $22(28.9)$ & $9(11.8)$ & $27(35.5)$ & $18(23.7)$ & $76(100.0)$ \\
\hline Pressure ulcer & $0(0.0)$ & $25(14.2)$ & $85(48.3)$ & $66(37.5)$ & $176(100.0)$ \\
\hline Other skin lesions & $7(20.0)$ & $7(20.0)$ & $9(25.7)$ & $12(34.3)$ & $35(100.0)$ \\
\hline Surgical procedure & $9(12.2)$ & $10(13.5)$ & $23(31.1)$ & $32(43.2)$ & $74(100.0)$ \\
\hline Transfusion process & $3(8.8)$ & $9(26.5)$ & $6(17.6)$ & $16(47.1)$ & $34(100.0)$ \\
\hline Patient identification & $3(12.5)$ & $4(16.7)$ & $7(29.2)$ & $10(41.7)$ & $24(100.0)$ \\
\hline Sample loss & $4(23.5)$ & $4(23.5)$ & $4(23.5)$ & $5(29.4)$ & $17(100.0)$ \\
\hline Hematoma & $0(0.0)$ & $1(5.3)$ & $12(63.2)$ & $6(31.6)$ & $19(100.0)$ \\
\hline Extravasation & $0(0.0)$ & $3(21.4)$ & $6(42.9)$ & $5(35.7)$ & $14(100.0)$ \\
\hline Delay in performing exam/procedure & $15(12.4)$ & $12(9.9)$ & $46(38.0)$ & $48(39.7)$ & $121(100.0)$ \\
\hline Prolonged fasting & $3(13.6)$ & $2(9.1)$ & $12(54.5)$ & $5(22.7)$ & $22(100.0)$ \\
\hline Evasion & $8(42.1)$ & $4(21.1)$ & $4(21.1)$ & $3(15.8)$ & $19(100.0)$ \\
\hline Technical, equipment or material handling failure & $4(22.2)$ & $5(27.8)$ & $4(22.2)$ & $5(27.8)$ & $18(100.0)$ \\
\hline Failure to identify material or instrument & $2(6.5)$ & $0(0.0)$ & $10(32.3)$ & $19(61.3)$ & $31(100.0)$ \\
\hline Related to childbirth & $5(25.0)$ & $6(30.0)$ & $8(40.0)$ & $1(5.0)$ & $20(100.0)$ \\
\hline Nutrition therapy & $6(15.8)$ & $7(18.4)$ & $11(28.9)$ & $14(36.8)$ & $38(100.0)$ \\
\hline Health Care Related Infection & $0(0.0)$ & $0(0.0)$ & $4(28.6)$ & $10(71.4)$ & $14(100.0)$ \\
\hline Failure during technique, procedure, or transport & $25(16.2)$ & $14(9.1)$ & $49(31.8)$ & $66(42.9)$ & $154(100.0)$ \\
\hline Failure to release technical report & $3(12.0)$ & $2(8.0)$ & $6(24.0)$ & $14(56.0)$ & $25(100.0)$ \\
\hline Unplanned removal of probe, drain, tube, or catheter & $22(28.6)$ & $15(19.5)$ & $25(32.5)$ & $15(19.5)$ & $77(100.0)$ \\
\hline Death & $0(0.0)$ & $2(20.0)$ & $6(60.0)$ & $2(20.0)$ & $10(100.0)$ \\
\hline Others & $7(14.3)$ & $5(10.2)$ & $14(28.6)$ & $22(46.9)$ & $49(100.0)$ \\
\hline Total & $194(14.7)$ & $173(13.1)$ & $448(34.0)$ & $501(38.1)$ & $1316(100.0)$ \\
\hline
\end{tabular}


Table 2 - Annual characteristics of incidents according to place of occurrence, age group affected, day, shift and severity or harm, Montes Claros, Minas Gerais, Brazil, 2015

\begin{tabular}{|c|c|c|c|c|c|}
\hline Characteristics/Categories & $\begin{array}{l}2011 \\
\text { n (\%) }\end{array}$ & $\begin{array}{l}2012 \\
\text { n (\%) }\end{array}$ & $\begin{array}{l}2013 \\
\text { n (\%) }\end{array}$ & $\begin{array}{l}2014 \\
\text { n (\%) }\end{array}$ & $\begin{array}{l}\text { Total } \\
\text { n (\%) }\end{array}$ \\
\hline \multicolumn{6}{|l|}{ Place of occurrence } \\
\hline Neonatal/pediatric ICU & $20(24.7)$ & $19(23.5)$ & $21(25.9)$ & $21(25.9)$ & $81(6.2)$ \\
\hline General ICU & $2(4.1)$ & $7(14.3)$ & $21(42.8)$ & $19(38.8)$ & $49(3.7)$ \\
\hline Coronary ICU & $8(25.8)$ & $1(3.2)$ & $11(35.5)$ & 11(35.5) & $31(2.4)$ \\
\hline Emergency & $15(10.8)$ & $17(12.2)$ & $59(42.5)$ & $48(34.5)$ & 139 (10.6) \\
\hline Semi-intensive unit & $0(0.0)$ & $0(0.0)$ & $9(21.4)$ & $33(78.6)$ & $42(3.2)$ \\
\hline Adult hospitalization unit & $60(46.5)$ & $43(25.7)$ & 113() & 128() & $344(26.1)$ \\
\hline Pediatrics & 4 (11.4) & $1(2.9)$ & $9(25.7)$ & $21(60.0)$ & $35(2.7)$ \\
\hline Nursery & $0(0.0)$ & $2(22.2)$ & $3(33.3)$ & $4(44.5)$ & $9(0.7)$ \\
\hline Maternity & $12(32.4)$ & $5(13.5)$ & $9(24.3)$ & $11(29.8)$ & $37(2.8)$ \\
\hline Obstetric Center & 7 (16.3) & $6(14.0)$ & $7(16.3)$ & $23(53.4)$ & $43(3.3)$ \\
\hline Surgery Center & $9(8.0)$ & $20(17.7)$ & $37(32.7)$ & $47(41.6)$ & $113(8.6)$ \\
\hline Sterilized Material Center & $1(9.1)$ & $1(9.1)$ & $4(36.4)$ & $5(45.4)$ & $11(0.8)$ \\
\hline Imaging & $11(22.9)$ & $9(18.8)$ & $12(25.0)$ & $16(33.3)$ & $48(3.7)$ \\
\hline Laboratory & $10(10.3)$ & $10(10.3)$ & $40(41.3)$ & $37(38.1)$ & $97(7.4)$ \\
\hline Hemodynamics & $4(20.0)$ & $1(5.0)$ & $8(40.0)$ & $7(35.0)$ & $20(1.5)$ \\
\hline Pharmacy & $8(14.8)$ & $7(13.0)$ & $23(42.6)$ & $16(29.6)$ & $54(4.1)$ \\
\hline Clinical engineering & $3(20.0)$ & $4(26.7)$ & $5(33.3)$ & $3(20.0)$ & $15(1.1)$ \\
\hline Quality Office & $0(0.0)$ & $0(0.0)$ & $6(85.7)$ & $1(14.3)$ & $7(0.5)$ \\
\hline Blood Transfusion Agency & $2(10.0)$ & $7(35.0)$ & $7(35.0)$ & $4(20.0)$ & $20(1.5)$ \\
\hline Oncology & $1(4.8)$ & $3(14.3)$ & $11(52.3)$ & $6(28.6)$ & $21(1.6)$ \\
\hline Nephrology & $1(4.8)$ & $1(4.8)$ & $12(57.1)$ & $7(33.3)$ & $21(1.6)$ \\
\hline Hotelery & $10(23.3)$ & $6(14.0)$ & 8 (18.6) & $19(44.1)$ & $43(3.3)$ \\
\hline Other diagnostic services & $3(20.0)$ & $1(6.7)$ & $7(46.7)$ & $4(26.8)$ & $15(1.1)$ \\
\hline Nutrition Therapy & $3(15.0)$ & $2(10.0)$ & $6(30.0)$ & $9(45.0)$ & $20(1.5)$ \\
\hline Total & $194(14.8)$ & $173(13.2)$ & $448(34.0)$ & $501(38.0)$ & $1316(100.0)$ \\
\hline \multicolumn{6}{|l|}{ Age group of patients } \\
\hline Newborn & $41(28.6)$ & $30(21.0)$ & $36(25.2)$ & $36(25.2)$ & $143(30.3)$ \\
\hline Child & $13(24.5)$ & $6(11.3)$ & $21(39.7)$ & $13(24.5)$ & $53(11.2)$ \\
\hline Adolescent & $3(27.3)$ & $5(45.4)$ & $1(9.1)$ & $2(18.2)$ & $11(2.3)$ \\
\hline Adult & $96(55.5)$ & $60(34.7)$ & $13(7.5)$ & $4(2.3)$ & $173(36.7)$ \\
\hline Elderly & $41(44.6)$ & $27(29.3)$ & $18(19.6)$ & $6(6.5)$ & $92(19.5)$ \\
\hline Total & $194(41.1)$ & $128(27.1)$ & 89 (18.9) & 61 (12.9) & $472(100.0)$ \\
\hline \multicolumn{6}{|l|}{ Day the event occurred } \\
\hline Sunday & 19 (14.6) & $20(15.4)$ & $46(35.4)$ & 45 (34.6) & $130(9.9)$ \\
\hline Monday & $42(18.0)$ & $30(12.9)$ & $72(30.9)$ & $89(38.2)$ & $233(17.7)$ \\
\hline Tuesday & $28(14.0)$ & $19(9.5)$ & $64(32.0)$ & $89(44.5)$ & $200(15.2)$ \\
\hline Wednesday & $32(13.6)$ & $36(15.3)$ & $85(36.0)$ & $83(35.1)$ & $236(17.9)$ \\
\hline Thursday & $24(12.3)$ & $30(15.4)$ & 68 (34.9) & $73(37.4)$ & $195(14.8)$ \\
\hline Friday & $29(15.0)$ & $23(11.9)$ & $70(36.3)$ & $71(36.8)$ & $193(14.7)$ \\
\hline Saturday & $20(15.5)$ & $15(11.6)$ & $43(33.3)$ & $50(39.6)$ & $128(9.8)$ \\
\hline Total & $194(14.7)$ & $173(13.1)$ & $448(34.0)$ & $501(38.2)$ & $1316(100.0)$ \\
\hline \multicolumn{6}{|l|}{ Shift the event occurred } \\
\hline Morning & $62(18.6)$ & $44(13.2)$ & $148(44.5)$ & $79(23.7)$ & $333(32.7)$ \\
\hline Afternoon & $59(19.0)$ & $44(14.2)$ & $139(44.9)$ & $68(21.9)$ & $310(30.5)$ \\
\hline Night & $72(19.2)$ & $73(19.5)$ & $155(41.3)$ & $75(20.0)$ & $375(36.8)$ \\
\hline Total & $193(19.0)$ & $161(15.8)$ & $442(43.4)$ & $222(21.8)$ & $1018(100.0)$ \\
\hline \multicolumn{6}{|l|}{ Severity or harm from event } \\
\hline Grade IV & $49(21.0)$ & $43(18.5)$ & $59(25.3)$ & $82(35.2)$ & $233(17.9)$ \\
\hline Grade III & $133(12.8)$ & $126(12.1)$ & $379(36.6)$ & $400(38.5)$ & $1038(79.7)$ \\
\hline Grade II & $9(60.0)$ & $2(13.3)$ & 3 (20.0) & $1(6.7)$ & $15(1.2)$ \\
\hline Grade I & $3(18.8)$ & $2(12.5)$ & $5(31.3)$ & $6(37.4)$ & $16(1.2)$ \\
\hline Total & $194(14.9)$ & $173(13.3)$ & $446(34.2)$ & $489(37.6)$ & $1302(100.0)$ \\
\hline
\end{tabular}

Note: $I C U=$ Intensive Care Unit 
Table 3 - Types of event according to severity or harm, Montes Claros, Minas Gerais, Brazil, 2015

\begin{tabular}{|c|c|c|c|c|c|}
\hline \multirow{2}{*}{ Type of event } & \multicolumn{4}{|c|}{ Severity or harm } & \multirow{2}{*}{$\begin{array}{l}\text { Total } \\
\text { n }(\%)\end{array}$} \\
\hline & $\begin{array}{c}\text { Grade IV } \\
\text { n (\%)* }\end{array}$ & $\begin{array}{c}\text { Grade III } \\
\text { n (\%) }\end{array}$ & $\begin{array}{c}\text { Grade II } \\
\text { n (\%) }\end{array}$ & $\begin{array}{c}\text { Grade I } \\
\text { n (\%) }\end{array}$ & \\
\hline Medication supply chain & $40(16.2)$ & $203(82.2)$ & $3(1.2)$ & $1(0.4)$ & $247(100.0)$ \\
\hline Falls & $19(25.0)$ & $57(75.0)$ & $0(0.0)$ & $0(0.0)$ & $76(100.0)$ \\
\hline Pressure ulcer & $0(0.0)$ & $174(100.0)$ & $0(0.0)$ & $0(0.0)$ & $174(100.0)$ \\
\hline Other skin lesions & $1(3.3)$ & $29(96.7)$ & $0(0.0)$ & $0(0.0)$ & $30(100.0)$ \\
\hline Surgical procedure & $12(16.2)$ & $58(78.4)$ & $2(2.7)$ & $2(2.7)$ & $74(100.0)$ \\
\hline Transfusion process & $10(29.4)$ & $24(70.6)$ & $0(0.0)$ & $0(0.0)$ & $34(100.0)$ \\
\hline Patient identification & $13(54.2)$ & $11(45.8)$ & $0(0.0)$ & $0(0.0)$ & $24(100.0)$ \\
\hline Sample loss & 3 (18.8) & $13(81.2)$ & $0(100.0)$ & $0(0.0)$ & $16(100.0)$ \\
\hline Hematoma & $0(0.0)$ & $18(94.7)$ & $1(5.3)$ & $0(0.0)$ & $19(100.0)$ \\
\hline Extravasation & $0(0.0)$ & $13(100.0)$ & $0(0.0)$ & $0(0.0)$ & $13(100.0)$ \\
\hline Delay in performing exam/procedure & $18(14.9)$ & $101(83.5)$ & $1(0.8)$ & $1(0.8)$ & $121(100.0)$ \\
\hline Prolonged fasting & $0(0.0)$ & $19(95.0)$ & $0(0.0)$ & $1(5.0)$ & $20(100.0)$ \\
\hline Evasion & $7(36.8)$ & $11(57.9)$ & $1(5.3)$ & $0(0.0)$ & $19(100.0)$ \\
\hline Technical, equipment or material handling failure & $5(27.8)$ & $12(66.7)$ & $1(5.5)$ & $0(0.0)$ & $18(100.0)$ \\
\hline Failure to identify material or instrument & $21(67.7)$ & $10(32.3)$ & $0(0.0)$ & $0(0.0)$ & $31(100.0)$ \\
\hline Related to childbirth & $7(35.0)$ & $12(60.0)$ & $1(5.0)$ & $0(0.0)$ & $20(100.0)$ \\
\hline Nutrition therapy & $8(21.1)$ & $29(76.3)$ & $1(2.6)$ & $0(0.0)$ & $38(100.0)$ \\
\hline Health Care Related Infection & $3(21.4)$ & $11(78.6)$ & $0(0.0)$ & $0(0.0)$ & $14(100.0)$ \\
\hline Failure during technique, procedure, or transport & $30(19.6)$ & $116(75.8)$ & $3(2.0)$ & $4(2.6)$ & $153(100.0)$ \\
\hline Failure to release technical report & $5(20.0)$ & $20(80.0)$ & $0(0.0)$ & $0(0.0)$ & $25(100.0)$ \\
\hline Unplanned removal of probe, drain, tube, or catheter & $4(5.2)$ & $72(93.5)$ & $1(1.3)$ & $0(0.0)$ & $77(100.0)$ \\
\hline Death & $0(0.0)$ & $3(30.0)$ & $0(0.0)$ & $7(70.0)$ & $10(100.0)$ \\
\hline Others & $27(55.1)$ & $22(44.9)$ & $0(0.0)$ & $0(0.0)$ & 49 (100.0) \\
\hline Total & $233(17.9)$ & $1038(79.6)$ & $15(1.2)$ & $16(1.3)$ & $1302(100.0)$ \\
\hline
\end{tabular}

Table 4 presents the causes and actions for incidents cited in the spontaneous reports studied. The main events were related to noncompliance with the routine/protocol (368, $29.7 \%$ ). It is pertinent to clarify that $18.5 \%$ of the notifications did not contain a description of the cause of the incident and consequently this data could not be analyzed.

The actions proposed to prevent recurrence of incidents were described in $80.9 \%$ of the notifications analyzed, according to Table 5 . The most frequently cited were: modify the routine/protocol $399(30.1 \%)$, provide guidance $280(21.1 \%)$, and training $224(17 \%)$.

Table 4 - Cause of the events, Montes Claros, Minas Gerais, Brazil, 2015

\begin{tabular}{lrr}
\hline \multicolumn{1}{c}{ Causes } & $\mathbf{n}$ & $\mathbf{~} \%$ \\
\hline Lack of routine & 32 & 2.6 \\
Noncompliance with routine & 368 & 29.7 \\
Inefficient Routine & 251 & 20.3 \\
Overload & 38 & 3.1 \\
Inadequate scaling & 45 & 3.6 \\
Untrained employee/team & 80 & 6.5 \\
Lack of attention/omission & 43 & 3.5 \\
Communication failure & 170 & 13.7 \\
Inappropriate physical environment & 8 & 0.6 \\
Inherent patient risk & 109 & 8.8 \\
Absence of equipment/material/medication & 84 & 6.8 \\
Inadequate operation of materials/equipment & 10 & 0.8 \\
Total & 1238 & 100.0 \\
\hline
\end{tabular}

Tabela 5 - Proposed action to prevent recurrence of incidents, Montes Claros, Minas Gerais, Brazil, 2015

\begin{tabular}{lrr}
\hline \multicolumn{1}{c}{ Action } & n & \multicolumn{1}{c}{ \% } \\
\hline Carry out training & 224 & 17.0 \\
Provide counseling & 280 & 21.1 \\
Follow routine & 192 & 14.5 \\
Modify routine & 399 & 30.1 \\
Create/implement form/check list & 43 & 3.2 \\
Perform process interaction & 35 & 2.6 \\
Acquiring/ordering material/staff/personnel & 127 & 9.5 \\
Intervention by clinical director & 22 & 1.7 \\
Perform preventive/corrective maintenance & 4 & 0.3 \\
No action & 314 & 19.1 \\
Total & 1416 & 100.0 \\
\hline
\end{tabular}

\section{DISCUSSION}

The findings of this study on the prevalence of incidents and their evolution in the period evaluated can be considered high and show a worrying reality, which should be analyzed carefully. Similar results were also found in the literature. In Brazil, in particular, research carried out in three teaching hospitals in Rio de Janeiro identified an incidence of $7.6 \%$ of patients who suffered adverse events, $66.7 \%$ of which were considered preventable ${ }^{(12)}$. However, the results of a study carried out in a hospital in the 
South of the country showed that the prevalence of reported incidents reached $1.1 \%$ of all admissions ${ }^{(13)}$. Research that measured the prevalence of adverse events in five Latin American countries showed that of a total of 11,379 inpatients, 1191 had at least one adverse event. The estimated point prevalence reached $10.5 \%$, more than $28 \%$ of these caused disability and $6 \%$ were associated with patient death ${ }^{(14)}$. Internationally, between $2.9 \%$ and $16.6 \%$ of hospitalized patients are affected by adverse events such as periand postoperative complications, medication errors, health carerelated infections or bed falls ${ }^{(15)}$.

In terms of the temporal evolution of spontaneous notification of incidents verified in the present work, the significant increase with the passage of time could demonstrate greater professionals maturity and adoption of the safety policy. A similar study, which analyzed notifications that occurred between 2008 and 2012, also indicated an increase in the number of reported incidents ${ }^{(13)}$.

In Brazil, research that evaluated the frequency of screening for potential adverse outcomes in admissions to the Unified Health System, including admissions of adults in the medical and surgical clinics, showed relevant results: a frequency of 3.6 potential adverse outcomes was found per 1,000 hospitalizations for both clinics, higher in the medical clinic $(5.3$ per 1,000$)$ compared to the surgical $(1.3$ per 1,000$)$. In the medical clinic, the elderly were predominant; with longer average hospital stay, higher mortality rate and lower total cost of hospitalization. The most frequent adverse tracing factor was hospital-acquired pneumonia. The highest hospitalization expenses were related to hospital sepsis. Potential adverse outcome scanners presented high chances of death, even with the introduction of variables such as intensive care and surgery. Thus, the high frequency of adverse outcomes in hospitalizations signals the need to develop monitoring strategies and improvements aimed at patient safety ${ }^{(9)}$.

Another study analyzed the characteristics of avoidable adverse events among inpatients based on the medical records sampled at three teaching hospitals in the state of Rio de Janeiro. The results were similar to those found in the present study. In the sample of 1,103 patients, 65 preventable adverse events were identified among the 56 patients who were victims of this type of incident. Healthcare associated infections accounted for $24.6 \%$; Surgical and/or anesthetic complications, $20.0 \%$; Harm due to delay or failure in diagnosis and/ or treatment, 18.4\%; Pressure ulcers, 18.4\%; Complications of venipuncture, $7.7 \%$; Harm due to falls, $6.2 \%$; and harm consequent to drug administration, $4.6 \%$. It should be noted that avoidable adverse events accounted for an additional 373 days of hospital stay. This characterization indicates that hospital managers and health professionals involved in inpatient care should prioritize the available and consolidated actions with a view to reducing such events, these include, hand hygiene, pressure ulcer prevention, encouragement of adherence to the protocol and clinical guidelines, and the establishment of continuing education programs for health workers ${ }^{(16)}$.

The high proportion of patients with preventable incidents and adverse events expresses the relevance of the problem and the urgency for actions that minimize the occurrence of unnecessary and avoidable harm to the patient. However, it should be emphasized that comparison between the results of this study with others is impaired because of different methods for incident identification and because of the specific characteristics of hospitals studied.

There are several methods of detecting these incidents, each with its advantages and disadvantages, such that an analysis of spontaneous notifications is only one of these. Throughout the world, voluntary notification is the most commonly used, because it is simpler and less expensive. However, there is still underreporting, despite recommendations that such information is not used for disciplinary and punitive purposes. In addition, other limitations of this method include absence of adequate information systems, fear of litigation, reluctance to report one's own mistakes, insufficient knowledge about the importance of events, and a lack of effective change following notification. Nevertheless, this method of communication is the most useful to provide behavioral changes, demonstrating the benefits of producing incident reports, since it allows learning from personal mistakes. The presence of a multi-professional volunteer safety team can facilitate the preparation of reports and promote the creation of a safety culture ${ }^{(13,17)}$.

In addition, it is considered necessary to elucidate concepts on the subject, which should be performed by risk managers or service leaders in the area of quality management and patient safety. An approach of all staff members to the content and taxonomy of patient safety is important for a universal language to be adopted and for mutual understanding in the correct communication of incidents, errors and adverse events in the service ${ }^{(7)}$.

The hospitalization units, emergency department and surgical center were the sectors responsible for most of the notifications, which is in line with the results of another study in which the hospitalization, intensive therapy and intensive care units accounted for the largest number occurrences of this nature. The higher frequency in hospitalization units may be related to the greater number of beds and, consequently, to a higher number of patients attended ${ }^{(13)}$.

In the present investigation, adults were the most affected by incidents, whereas in another study the presence of reported incidents predominated among patients aged 13 to 59 years, $377(51.8 \%)$; while those aged 60 years or over were involved in $303(41.6 \%)$ of the reported incidents ${ }^{(13)}$. Research performed in Spain observed a prevalence in patients over 62 years of age ${ }^{(18)}$.

The medication supply chain involved most of the incidents reported by the professionals in this study, which highlights the complexity of the medication system and the need for special attention to make this safer. In the literature, medication errors are responsible for disturbing findings: they are present in $16.7 \%$ of all incidents, ranking the second most frequent ${ }^{(13)}$. In another study, these corresponded to $62.7 \%{ }^{(19)}$. Likewise, in a survey carried out in Spain, the finding of $5.21 \%$, also underscored this as one of the most frequent types of incident ${ }^{(18)}$. A study carried out in two public university hospitals in Ireland found that in a sample population of 624 hospitalized patients, there was a $16 \%$ frequency of medication errors with impact on care, $2 \%$ of these with a severe or a major potential to compromise drug therapy and in $1 \%$ of the cases patients, there could be unplanned readmission within three months ${ }^{(20)}$. 
Awareness of the types of errors prevalent in the hospital and of the subsystems involved is fundamental for improvement in the medication administration process. However, there is evidence that practitioners do not know all medication errors, which leads to poor reporting ${ }^{(19)}$. In addition, the observed number of incidents involving medications suggests that it is even greater in other contexts that do not share the level of quality seen in the scenario of the institution studied in the present research. Thus, it is necessary to implement a method for identifying adverse drug events and reviewing the medication system in the institution; these are measures that favor the monitoring and implementation of defense mechanisms, barriers and protection for improvement of patient safety. It is important to highlight the impact of medication supply chain incidents on nursing care, since when these occur, it is necessary to monitor the patient due to adverse events, as well as prolong the hospitalization time, intervene with other medications and sometimes even subject the patient to invasive procedures ${ }^{(21)}$.

The hospital professionals in the scenario of this research, through spontaneous notifications, indicated the main causes for the occurrence of incidents were factors related to noncompliance with the routine/protocol and also outlined actions that they consider pertinent to avoid recurrence of incidents, such as: modifications to the routine/protocol, and provide orientation and training. The national and international literature on the subject corroborates these findings $s^{(1-3,6,8,22)}$. Human resources and quality management managers should be in continuous contact with the hospital staff in order to obtain feedback on patient safety in terms of training and management of teams. Through this interaction, it will be possible to develop policies, strategies and provide the necessary support in case of incidents, whenever detected. Although it has not been predominant, work overload must be prevented, which requires a detailed and dynamic analysis of the peculiarities of each sector ${ }^{(6)}$, in addition to adequate staffing ${ }^{(2)}$.

Studies in Sweden ${ }^{(1)}$ and Iran $^{(3)}$ have shown that cultural change is a challenge and takes up time in the hospital routine. The practice of permanent education, in this context, allows a reflection on the various issues that are present in the daily practice. Ensuring patient safety requires a variety of actions, from professional training to changing health practices. In order to provide quality care, it is necessary that the work processes be reviewed, and have properly qualified and trained health professionals. It is also important for the institution to provide technologies that favor this improvement. These recommendations are indicated in national ${ }^{(2,8)}$ and international studies ${ }^{(1,3)}$, collaborating to prevent incidents and their recurrence ${ }^{(3)}$.

\section{Study limitations}

The results should be considered in the light of certain limitations. It is a cross-sectional study, which evaluated only the association between variables, without the possibility of defining a causal relationship. The sample, although representative, was restricted to a single hospital, which hinders the generalization of the results. In important variables, underreporting was frequent, which may have made it difficult to obtain a more accurate vision of the reality studied.

\section{Contributions to Nursing, health or public policy}

This research provided a comprehensive analysis of incidents in a general hospital and reiterated the potential of spontaneous reporting as a mechanism that contributes to patient safety. It is believed that the results may favor greater knowledge on the topic and form a basis to guarantee quality care, mainly through a greater awareness of the professionals and managers regarding the implementation of notification culture in the institutions, in order to stimulate appropriate management of the incident and overcome the fear of punishment.

\section{CONCLUSION}

The study allowed an evaluation of incidents reported spontaneously in a general hospital. The results showed a considerable prevalence of incidents and an increase in the number of notifications during the investigation period. This revealed a reality that requires special attention from the managers and collaborators. However we observed the development of patient safety culture and a greater degree of maturity among the health professionals.

A relevant situation was also verified in the hospitalization units; the emergency and surgical centers were responsible for most notifications; for adult clients and the medication supply chain, which involved most of the reported incidents, the results reaffirm the complexity of the medication system and the need for strategies to make it safer. In addition, the main causes of incidents involved noncompliance with the routine/ protocol, and professionals suggested some actions to avoid their recurrence, such as changing the routine/protocol and providing guidance and training.

This situation reveals that cultural change is a challenge that demands time in the routine of hospitals, besides the implementation of various effective actions that guarantee patient safety.

\section{REFERENCES}

1. Burström L, Letterstål A, Engström ML, Berglund A, Enlund M. The patient safety culture as perceived by staff at two different emergency departments before and after introducing a flow-oriented working model with team triage and lean principles: a repeated cross-sectional study. BMC Health Serv Res [Internet]. 2014[cited 2016 Jan 18];14(296):1-12. Available from: http:// bmchealthservres.biomedcentral.com/articles/10.1186/1472-6963-14-296

2. Fassini $P$, Hahn GV. Riscos à segurança do paciente em unidade de internação hospitalar: concepções da equipe de enfermagem. Rev Enferm UFSM [Internet]. 2012[cited 2016 Jan 19];2(2):290-9. Available from: https://periodicos.ufsm.br/reufsm/article/view/4966/3753 
3. Jahromi ZB, Parandavar N, Rahmanian S. Investigating factors associated with not reporting medical errors from the medical team's point of view in Jahrom, Iran. Global J Health Sci[Internet]. 2014[cited 2016 Jan 22];6(6):96-104. Available from: https:// www.ncbi.nlm.nih.gov/pmc/articles/PMC4825519/pdf/GJHS-6-96.pdf

4. Pancieri AP, Santos BP, Avila MAG, Braga EM. Safe surgery checklist: analysis of the safety and communication of teams from a teaching hospital. Rev Gaúcha Enferm[Internet]. 2013[cited 2016 Mar 11];34(1):71-8. Available from: http://dx.doi.org/10.1590/ S1983-14472013000100009

5. Paranaguá TTB, Bezerra ALQ, Camargo e Silva AEB, Azevedo Filho FM. Prevalence of no harm incidents and adverse events in a surgical clinic. Acta Paul Enferm [Internet]. 2013[cited 2015 Oct 12];26(3):256-62. Available from: http://dx.doi.org/10.1590/ S0103-21002013000300009

6. Novaretti MCZ, Santos EV, Quitério LM, Daud-Gallotti RM. Sobrecarga de trabalho da Enfermagem e incidentes e eventos adversos em pacientes internados em UTI. Rev Bras Enferm [Internet]. 2014[cited 2016 Jan 19];67(5):692-9. Available from: http://dx.doi. org/10.1590/0034-7167.2014670504

7. Leitão IMTA, Oliveira RM, Leite SS, Sobral MC, Figueiredo SV, Cadete MC. Análise da comunicação de eventos adversos na perspectiva de enfermeiros assistenciais. Rev Rene [Internet]. 2013[cited 2016 Jan 19];14(6):1073-83. Available from: http://www. periodicos.ufc.br/index.php/rene/article/view/3713/2933

8. Rocha JP, Silva AEBC, Bezerra ALQ, Sousa MRG, Moreira IA. Eventos adversos identificados nos relatórios de enfermagem em uma clínica pediátrica. Cienc Enferm [Internet]. 2014[cited 2016 Jan 14];20(2):53-63. Available from: http://dx.doi.org/10.4067/ S0717-95532014000200006

9. Dias MAE, Martins M, Navarro N. Adverse outcome screening in hospitalizations of the Brazilian Unified Health System. Rev Saúde Pública [Internet]. 2012[cited 2016 Jan 22];46(4):719-29. Available from: http://dx.doi.org/10.1590/S0034-89102012005000054

10. Carneiro FS, Bezerra ALQ, Silva AEBC, Souza LS, Paranaguá TTB, Branquinho NCSS. Eventos adversos na clínica cirúrgica de um hospital universitário: instrumento de avaliação da qualidade. Rev Enferm UERJ [Internet]. 2011[cited 2016 Jan 19];19(2):127-33. Available from: http://www.facenf.uerj.br/v19n2/v19n2a06.pdf

11. Brasil. Ministério da Saúde. Agência Nacional de Vigilância Sanitária. Resolução - RDC n 36, de 25 de julho de 2013 . Institui ações para a segurança do paciente em serviços de saúde e dá outras providências. Brasília (DF): Ministério da Saúde, 2013.

12. Mendes W, Martins M, Rozenfeld S, Travassos C. The assessment of adverse events in Brazilian hospitals. Int J Qual Health Care [Internet]. 2009 [cited 2016 Jan 19];21(4):279-84. Available from: http://intqhc.oxfordjournals.org/content/21/4/279.full.pdf

13. Lorenzini E, Santi JAR, Báo ACP. Patient safety: analysis of the incidents notified in a hospital, in south of Brazil. Rev Gaúcha Enferm [Internet]. 2014 [cited 2016 Jan 21];35(2):121-7. Available from: http://dx.doi.org/10.1590/1983-1447.2014.02.44370

14. Aranaz-Andrés JM, Aibar-Remón C, Limón-Ramírez R, Amarilla A, Restrepo FR, Urroz O, et al. Prevalence of adverse events in the hospitals of five Latin American countries: results of the 'Iberoamerican study of adverse events' (IBEAS). BMJ Qual Saf. 2011;20(12):1043-51.

15. Magalhães AMM, Dall'Agnol CM, Marck PB. Nursing workload and patient safety - a mixed method study with an ecological restorative approach. Rev Latino-Am Enfermagem [Internet]. 2013[cited 2016 Jan 19];21(spe):146-54. Available from: http:// dx.doi.org/10.1590/S0104-11692013000700019

16. Mendes W, Pavão ALB, Martins M, Moura MLO, Travassos C. The feature of preventable adverse events in hospitals in the State of Rio de Janeiro, Brazil. Rev Assoc Med Bras [Internet]. 2013[cited 2016 Jan 19];59(5):421-8. Available from: http://dx.doi. org/10.1016/j.ramb.2013.03.002

17. Garrouste-Orgeas M, Philippart F, Bruel C, Max A, Lau N, Misset B. Overview of medical errors and adverse events. Ann Intensive Care [Internet]. 2012[cited 2016 Jan 17];2(1):1-9. Available from: https://www.ncbi.nlm.nih.gov/pmc/articles/PMC3310841/ $\mathrm{pdf} / 2110-5820-2-2 . p d f$

18. Merino P, Álvarez J, Martín MC, Alonso, Gutiérrez S. Adverse events in Spanish intensive care units: the SYREC study. Int J Qual Health Care [Internet]. 2011[cited 2016 Jan 19];24(2):105-13. Available from: http://intqhc.oxfordjournals.org/content/ intqhc/24/2/105.full.pdf

19. Camerini GF, Silva DL. Segurança do paciente: análise do preparo de medicação intravenosa em hospital da rede sentinela. Texto Contexto Enferm [Internet]. 2011[cited 2016 Jan 19];20(1):41-9. Available from: http://dx.doi.org/10.1590/ S0104-07072011000100005

20. Grimes TC, Duggan CA, Delaney TP, Graham IM, Conlon KC, Deasy E, et al. Medication details documented on hospital discharge: cross-sectional observational study of factors associated with medication non-reconciliation. Br J Clin Pharmacol [Internet]. 2011[cited 2016 Jan 19];71(3):449-57. Available from: https://www.ncbi.nlm.nih.gov/pmc/articles/PMC3045555/pdf/ bcp0071-0449.pdf

21. Roque KE, Melo ECP. Avaliação dos eventos adversos a medicamentos no contexto hospitalar. Esc Anna Nery Rev Enferm [Internet]. 2012 [cited 2016 Jan 19];16(1):121-7. Available from: http://dx.doi.org/10.1590/S1414-81452012000100016

22. Oliveira RB, Melo ECP. O sistema de medicação em um hospital especializado no município do Rio de Janeiro. Esc Anna Nery Rev Enferm [Internet]. 2011 [cited 2016 Jan 22];15(3):480-9. Available from: http://dx.doi.org/10.1590/S1414-81452011000300006 